\title{
The Effect of Health Problems on Quality of Work Life among Garments Workers in Dhaka City
}

\author{
Shahria Sattar \\ Medical officer, \\ Bangladesh Secretariat Clinic, \\ Dhaka, Bangladesh \\ Shahria.sion@gmail.com \\ Kamrul Laila \\ Medical officer, \\ Bangladesh Secretariat Clinic, \\ Dhaka, Bangladesh \\ drlaila28@gmail.com
}

DOI: 10.31364/SCIRJ/v6.i7.2018.P0718539

http://dx.doi.org/10.31364/SCIRJ/v6.i7.2018.P0718539

\begin{abstract}
Background: The quality of organization depends on the quality of work, which controlled by workers. The problem of workers' adjustment to their work situation is reflected through their perception of QWL.

Aims and Objectives: The present study attempts to measure the level of Quality of work life of the workers of garment industries in selected workplace and also to assess the effect of health problems on quality of work life.

Methodology: The garments were chosen purposively. On non-probability purposive technique the respondents were selected and interviewed after their verbal consent to participate in the study. Data were collected by using a structured, pre-tested questionnaire.

Observation and result: The mean health score was higher among the divorced respondents and with monthly income group tk. 5000 and above. The mean of the health score was lowest among those who worked in the sewing section. Quality of work life score varied with different physical problems.

Conclusion: The mean quality of work life among the garment worker is found to be below average so the concern authority do need immediate action to improve the quality of work life.
\end{abstract}

Indexed Terms: Health problems, Quality of work life, respondents, health score

\section{Introduction}

Bangladesh is a developing country with a density of population of about 150 million. Due to rapid growth rate of population, it is facing problems in employment, health, housing, environment, etc.

From the last third decade, garment industries gradually developed and by the time being it became one of the most promising industrial domain in Bangladesh.

In Bangladesh, the garment industry contributes a good support to the economy of our country and it is the prime mover of our economy which propels other sectors such as transport, banking, shipping, clearing and forwarding. 
Now Readymade Garment (RMG) is the leading sector of Bangladesh in terms of employment, production and foreign exchange earnings.[1],[2]. This sector has uplifted the neglected section of the population, thus radically transforming the socio-economic condition of the country.

Readymade garment (RMG) alone earned about $78 \%$ of the yearly foreign exchange earning of the country.[1],[2].

Garments provide employment of about 3.5 million of people. This empowerment and employment raised awareness regarding children education, health safety, population control, disaster management and many more needs.[1],[2].

Garment workers are the common element in every garment because without the support of workers, machine remains idle and money tied up. Work is the core of life, it means autonomy, it pays off in success and establishes self-respect or self-worth.[3].

Post liberalization environment give rise to number of industries including garments which brings competitive business war in Bangladesh. Garments in Bangladesh have to think how to face them and survive. Every organization is facing unique problems, some organizations may have old technology, some may lag in financial strength and some may pause be having obsolete products, some may not have providing good working environment, and some may not have job security but any of which may affect the quality of work life. However many garments are not exceptional one to face the same. Any attempt at improving the performance of the organization can be successful only if the organization is able to develop a strong quality work life.

The quality of organization depends on the quality of work, which controlled by workers. The problem of workers' adjustment to their work situation is reflected through their perception of QWL.

From early seventies a good deal of studies has been done on quality of work life (QWL). A programme lunched at Tarrytown (New York) in 1977 by General Motors on QWL was indeed a Challenge and today it is rightly regarded as a milestone in QWL movement. Tarrytown event has shown successfully- how the workers have actively participated in maintaining industrial democracy, which is believed to be a necessary precondition for making industrial environment congenial to production as well as environment; and maintaining "industrial democracy" means maintaining quality of work life .[4].

The relationships between individuals and organizational factors that existing in the working environment can be explained through Quality of work life. The workers can satisfy important personal needs through their experiences in the organization. It is focusing strongly on providing a work environment conducive to satisfy individual needs. It is assumed that if employees have more positive attitudes about the organization and their productivity increases, everything else being equal, the organization should be more effective.[2],[5].

Quality of work life has direct impact on human outcomes and reduces absenteeism, minor accidents, grievances and quits. It benefits also include financial services, consumer services, career counseling, employee information reports, retirement benefits, recreational services and health safety measures.[2],[3],[6].

Enhancing QWL will result in productivity improvement and gains from productivity improvements in turn will strengthen QWL.[ 2],[7]. 
QWL programs are desirable for both human and performance needs and it provides the order needs of workers as well as their basic needs. [8]. Studies on QWL has been conducted in manufacturing organization in many countries but studies on QWL in Bangladesh are rare to found.

So, considering the above factors, the present study attempts to measure the level of Quality of work life of the workers of garment industries in selected workplace. Also the proposed study aims to assess the effect of health problems on quality of work life in garments workers.

The problem of workers' adjustment to their work situation is reflected through their quality of work life and health conditions. So, knowledge of quality of work life and health condition is vital towards understanding their problems with their work place and also towards adopting suitable policies for making them happier with their work situation.

It is important to know how garment industries affect workers' health and wellbeing. If garment workers could know the causes of how they are being affected, they could be able to overcome the problems. If it is possible to make the information available to the planners of relevant department of government and non- government organizations who can then take appropriate actions to improve the situations.

The focal point of discussion in this study is to describe some important aspects of quality of work life and workers health problems (physical health) related to it.

\section{Methodology}

The cross-sectional study was conducted to assess the level of Quality of work life of the workers employed in different Garments located in Dhaka City and to assess the effects of health problems on QWL in garments workers.

The study was conducted from March 2010 to June 2010.A sample size of 110 workers taken from two garments. The garments were chosen purposively and depending upon easy communication and availability of samples or other relevant factors.

Both male \& female workers of the selected garments working in different working section like : sewing section, knitting section, finishing section, etc. holding different work designation like : helper, operator, iron man, packing man, poly packer, loader, knitting master, feder man, etc. were the study population. Samples are estimated by applying formula $: n=z 2 p q / d 2$

On non probability purposive technique the respondents were selected and interviewed after their verbal consent to participate in the study. Data were collected by using a structured, pre-tested questionnaire.

\section{Sinha and Sayeed's scale measuring the quality of work life:}

For measuring the quality of work life in this study, bangle version of Sinha and Sayeed`s scale as developed by Haque in 1991 was used The inventory developed by Sinha and Sayeed (1980) for measuring QWL having 85 items. Each of these item had a 7- point scale and the scale range from minimum 1 to maximum 7. The items were either in question or statement or quotation and the subjects were to encircle an appropriate numeral (1 to 7) furnished on the right side of each item according to their agreement or disagreement, satisfaction or dissatisfaction, feeling positively or negatively with the statement. The numerals encircled were added to give the total or overall QWL score. Thus the higher the total score, the higher the perceived QWL of the subject.[2],[9]. 


\section{The Inventory of subjective health (ISH) - subjective health related questionnaire:}

An inventory for subjective health developed by Dirken in 1967 was used to assess the complaints of the subjects regarding health. The original inventory consists of 58 questions concerning health complaints of various types, to which subject`s answer yes or no. Out of 58 questions, 48 questions are used to complete a score for an inverse approximation of general health. The other 10 items serve to stimulate concentration during the filling out of the form and to prevent the effects of irrelevant response-set. Possible range of scores varies from 0 to 48 . All scores were assumed to form an index of ISH.

About 2,500 workers from several industries were investigated for standardization and validation of this inventory. This inventory has been found significantly correlated with absenteeism.

Khaleque and Rahman in 1983 adapted version in Bengali of this inventory was used in the present study. The Bengali version of the scale has got 56 items instead of original 58 items. But at present, to interview the garment workers, this Bengali adapted version is shortened to 28 items which is used to assess the complaints of the workers regarding health.

\section{Data Collection procedure:}

After developing the relevant research instrument, selection of place of study and sample size all the respondents were briefed about the purpose of the study prior to the interview and data collection. The respondents were interviewed face to face by the researcher using structured questionnaire. Face to face interview was fruitful as many respondents were less literate and the subjective nature of the study sometimes required additional clarification and understanding.

The questions were asked in Bengali and explained in a simplified manner to avoid any error from faulty understanding. Random sampling was not done.

\section{Data Analysis:}

Documents of all respondents were checked and verified thoroughly to reduce any inconsistency. Then edited into computer, processed and tabulated to get a master sheet. Then coded data analysis was done by using Microsoft Statistical package for the social science (SPSS) version 11.5 for windows. (108) Frequency distribution was found. Percentages, means and standard deviation were calculated where necessary. To test the significance chi- square $(x 2)$, student`s t test, ANOVA were applied where necessary. Graphical software like tables and figures were used for creation of charts.

\section{Observation and result}

The mean health score was higher among the divorced respondents $(22.1429 \pm 1.84445)$ than unmarried or married respondents which was found to be statistically significant. It was may be due to less anxious family life, no draw back of the family life. The highest health score of the respondents with monthly income group tk. 5000 and above $(20.3750 \pm 1.92261)$ and the lowest health score of the 
respondents with monthly income below tk. 2000 (19.7143 \pm 1.38013$)$. This difference in mean health score between income groups was found not to be significant.

The mean of the health score was lowest among those who were illiterate (19.3214 \pm 1.76496$)$ and those who worked in the sewing section (19.9851 \pm 1.82982$)$. But these difference in the mean health score were not found to be significantly statistical.

The respondents who complained of cough had lower mean quality of work life score $(281.32 \pm 24.803)$ and was found statistically significant (Table I). The respondents who complained of suffering from discomfort in stomach had higher mean quality of work life score $(292.04 \pm 28.133)$ but this difference was found statistically not significant.

The mean quality of work life score $(288.90 \pm 27.563)$ of the respondents suffering from head ach was lower. And the mean quality of work life score $(284.24 \pm 25.287)$ among the respondents suffering from pain in or around eyes which was lower than those who were not suffering. This difference in mean quality of work life score was found statistically significant (Table II)

The respondents who did not complain of suffering from pain in bones or muscles had higher mean quality of work life score (299.80 $\pm 15.999)$. Those who complained of suffering from back pain had higher mean quality of work life score (291.95 \pm 27.444$)$ than those did not complaint.

Those who complained of suffering from rheumatic fever, tremor in hands had lower mean quality of work life score $(2872.3 \pm$ 28.119). The respondents who felt themselves lean and thin had higher mean quality of work life score $(292.40 \pm 27.401)$ than those who were not. And those who complained of suffering from senseless or severe pain in any extremities had higher mean quality of work life score $(293.41 \pm 30.221)$ but this difference in mean quality of work life score was found statistically not significant (Table III).

Most of the respondents (88) complained of facing small accidents and they had lower mean quality of work life score (290.53 \pm 27.708). This difference in mean quality of work life score was found statistically not significant (Table IV).

The score $(285.71 \pm 29.657)$ of the respondent who were often lazy or sleepy was lower but this difference in mean quality of work life score was found statistically not significant. The difference in mean quality of work life scores between the respondents who felt sleepy immediately coming home after work and who did not was higher. Presence of tiredness after awaking of the respondents who`s mean quality of work life score $(276.77 \pm 25.974)$ were lower. This difference in mean quality of work life score was found statistically significant (Table V).

Total health score showed positive correlation with total score of quality of working life $(r=0.390, p<0.001)$. Linear regression demonstrated a significant positive relationship $(\mathrm{F}(1,108)=19.372, \mathrm{p}<0.001)$. The coefficient of determination $(\mathrm{R} 2=0.152)$ indicated that only $15.2 \%$ of the variation in total score of quality of working life was explained by total health score (Table VI).

\section{Discussion:}


This descriptive type of cross sectional study conducted in two selected garments in Dhaka city determining the state of quality of work life and identification of physical health problems of one hundred and ten workers. The respondents were interviewed based on structured questionnaire constructed in line with the Sinha and Sayeed`s inventory for quality of work life (QWL) and inventory of subjective health for identifying physical health problems. Information of the sample was collected by using non-probability purposive sampling method.

People want to work in a place where they can succeed and feel their contribution is appreciated. They want to work in great work environment. The absence of this environment can push people to explore their opportunities. Organizations need employees connected to their mission and focused on delivering their products or services as efficiently and effectively as possible.[10].

The present study attempted to assess the quality of work life (QWL) in garment industries and also if quality of work life had any relationship with the effect of health problems on quality of work life.

It was found that $57 \%$ of the workers had complained of suffering from illness. whereas $43 \%$ of respondent did not complained for any type of illness.

Cough, pain in or around eyes, tiredness after awaking are the most significant health problem in relation to QWL. The fact is supported by other previous studies.[11].

A study done by Saha, N. K. on a sample of 540 workers in the tobacco industry found that $66.5 \%$ workers had records of post service illness and suffered from the diseases like cold and fever, headache, body pain and grip up one`s loins, gastric, dysentery, pain in the bowel, lung pain, respiratory problem, irregular menstruation, eye and ear diseases etc, one or several times in the year.[11].

A pilot survey on the health problems of industrial workers conducted by the National Institute of Occupation Health (NIOH) (1984), showed that the workers of the polluted industries are more prone to suffer from health problems like Indigestion, loss of appetite, abdominal pain, lethargy and depression and their bio-rhythms get disturbed. NIOH warns that if these problems are not attended properly at an early stage, they may lead to peptic ulcer and insomnia.[12].

Another study done by Chowdhudy N. S., among 184 garment workers of Dhaka city found that $9.8 \%$ of the workers had depression and $55.6 \%$ were unhappy.[13].

The mean health score of the respondents was $19.83 \pm 1.837$ and the correlation between quality of work life and subjective health was found to be significant and supported by other studies.[11].

In spite of the under -reporting there is evidence by WHO that the major groups of occupational diseases occur frequently. They include the pneumoconiosis and obstructive respiratory diseases caused by dust.[14].

On determining the relation between the total health score and dimensions of quality of work life, it was found that welfare measure was the best predictor of health score, which was followed by Supervision and communication. Working environment had least contribution on total health score of the workers. This result is similar with other studies.[11],[15].

Vaernes et.al. (1988) examine a group of 127 worker for health complaints, subjecting experience of their work environment, psychological defense, strategies and immunological factors. They found that the main health complaints were sleep disturbance or gastrointestinal problems. The workers also complained about allergies, breathing difficulties, tension, anxiety and depression due to the adverse working environment.[16]. 
The effect of demographic variables like age, gender, working sections, educational status, monthly income and current job experience were not significant on the total health score except for marital status. It was found that divorced respondents had more total health score than unmarried or married respondents.[11],[17],[18],[19]. May be unmarried or married people were more preoccupied about the thoughts of family and more concerned about their own future and the uncertainly of their family and relatives. This is also similar with other studies.[3],[11],[13],[17].

Female industrial workers in Bangladesh, those in the ready-made apparel sector, have been the subject of numerous studies and expositions. These studies tend to focus on hazardous work conditions, low and irregular wages, health, housing and transportation dilemmas and, more recently, on the effects of globalization on job security.

Labor activists, taking their cue from workers, focus on workers' security, safety and health as well on wage levels. Without doubt, steps to prevent workers' deaths or disability from fires resulting from employer negligence, or demanding fair wages received in due time, are matters that require urgent attention[20].

\section{CONCLUSION}

The mean quality of work life among the garment worker is found to be below average so the concern authority do need immediate action to improve the quality of work life. The correlation between quality of work life and subjective health was significant. High scores on quality of working life indicate better quality of working life and low scores on subjective health indicate better health and vice versa. So it can be concluded that quality of work life will create awareness to the authority of factory management, national legal authorities and leaders both for personal and public aspect.

\section{Recommendations}

Small sample size and limited area of investigation which might not be true representative of the whole population of the garments. So, before generalization, there is a need to conduct an in-depth study covering larger sample size and broader areas of investigation.

Based on the results of this study it is expected that the present findings might be helpful to know the quality of work life which is vital to understand the problems of the workers with their workplace and also to adopt suitable policies for making them happier with their work situation. It might serve as a basis for further research and studies.

\section{References:}

[1] BGMEA, Brief. CAFAXPO, 2010.

[2] Sattar, S., Relation of Job Related Factors with Different Dimensions of QWL. World J. P.H.,2018; 3(1): 16-22.

[3] Sadique, Dr. M. Z. The Impact of Designation, Experience and age on Existing and Expected Quality of work life : A Case Study of four Sugar Mills in Bangladesh. Daffodil Int. Univer. J. of Business and Economics, 2007; 2(1) : 155-156.

[4] Guest, R. H. Quality of work life- learning from Tarrytown. Harvard Business Review,1979; 57( 4), 76-87.

[5] Sinha, P. Quality of working life . Indian J. of Industrials Relations, 1982; 17(3): 373-394.

[6] Haque, A. B. M. Z. Quality of working life and Job satisfaction of Industrial workers in relation to size of the Organization. Bangladesh Psychol. Stud.1991; 2: 43 -55. 
[7] Walton, R. E. How to Counter Alienation in the Plant, Harvard Business Review, 1972; Nov-Dec.

[8] Wadud, N. Job Stress and QWL among Working Woman, Bangladesh Psychological studies, 1996 ; 6 :31-37.

[9] Sinha, P. and Sayeed, O. B. Measuring QWL : development of an inventory. The Indian J. of Social Work, 1980; 41(3): 219226.

[10] Ali, T. Akter, I. and Newaz, M. K. Employee perception regarding turnover decision- in context of Bangladesh Banking sector, BracUniver J. 2007; 4(2): 67-74.

[11] Saha, N. K. and Elias, S. Environmental Pollution and Quality of working Life in Tobacco Industries. J. Life Earth Science, $2005 ; 1(1): 21-24$

[12] NIOH survey on Health Problems of Industrial Workers, 1984.

[13] Chowdhury, N. S. Depression among workers in selected Garment Factories. NIPSOM, 2008.

[14] WHO Report on Study of Periodic Health Examinations of Workers exposed to Industrial Hazards, 1979.

[15] Anbarasan, V. and Mehta, N. An exploratory study on perceived Quality of Working life among Sales Professionals employed in Pharmaceutical, Banking, Finance and Insurance companies in Mumbi. 2009; April.

[16] Vaernes et al. Work and Stress, 1988; 2(1).

[17] Kanagalakshmi, L. and Nirmala, D. B. A Study on perception of QWL among Textile manufacturing workers in Tirunelveli.2003;

[18] Uddin, M. T. Islam, M. T. and Ullah, M. O. A Study on the Quality of Nurses of Government hospitals in Bangladesh, Proc. Pakistan Acad. Sci. 2006; 43(2) : 121-129.

[19] Hossain, M. M. and Rahman, M. A. A socio economic survey of the Female Garment Workers in Narayangonj. Islamic University Studies, 1991; 11: 30-41.

[20] Dina, M. S. The sexual harassment of the Industrial Workers : Strategies for intervention in Workplace and beyond, CPD dialog Report, 2003; 65: 1-22.

Table I: Distribution of respondents by presence of cough and quality of work life

\begin{tabular}{|l|r|r|r|r|}
\hline \multirow{2}{*}{$\begin{array}{l}\text { Whether suffering from } \\
\text { cough }\end{array}$} & \multicolumn{2}{|c|}{ Quality of work life } & \multirow{2}{*}{ Significance } & \\
\cline { 2 - 3 } & Mean & SD & \\
\cline { 1 - 3 } Yes (47) & 281.32 & 24.803 & $\begin{array}{l}\mathrm{t}=-3.521 \\
\text { d.f. }=108\end{array}$ & $<0.001$ \\
\hline No (63) & 299.21 & 27.452 & \\
\hline
\end{tabular}

Table II. Distribution of respondents by presence of headache, pain in or around eyes and quality of work life

\begin{tabular}{|c|c|c|c|c|}
\hline \multirow{2}{*}{$\begin{array}{c}\text { Whether suffering from } \\
\text { head ach }\end{array}$} & \multicolumn{2}{|c|}{ Quality of work life } & \multirow[t]{2}{*}{ Significance } & \multirow[t]{2}{*}{$\mathrm{p}$ - value } \\
\hline & Mean & SD & & \\
\hline Yes (77) & 288.90 & 27.563 & \multirow{2}{*}{$\begin{array}{l}\mathrm{t}=-1.553 \\
\text { d.f. }=108\end{array}$} & \multirow[t]{2}{*}{$>0.05$} \\
\hline No (33) & 297.79 & 27.427 & & \\
\hline
\end{tabular}




\begin{tabular}{|c|c|c|c|c|}
\hline \multicolumn{5}{|c|}{ Whether suffering from pain in and around eyes } \\
\hline Yes (67) & 284.24 & 25.287 & \multirow{2}{*}{$\begin{array}{l}\mathrm{t}=-3.653 \\
\text { d.f. }=108\end{array}$} & \multirow{2}{*}{$<0.001$} \\
\hline No (43) & 302.78 & 27.704 & & \\
\hline
\end{tabular}

Table III: Distribution of respondents by presence of musculoskeletal problems and quality of work life

\begin{tabular}{|c|c|c|c|c|}
\hline \multirow{2}{*}{$\begin{array}{c}\text { Whether suffering from } \\
\text { pain in bones or } \\
\text { muscles }\end{array}$} & \multicolumn{2}{|c|}{ Quality of work life } & \multirow[t]{2}{*}{ Significance } & \multirow[t]{2}{*}{$\mathrm{p}$ - value } \\
\hline & Mean & SD & & \\
\hline Yes (100) & 290.74 & 28.531 & \multirow{2}{*}{$\begin{array}{l}\mathrm{t}=-1.560 \\
\text { d.f. }=15.492\end{array}$} & \multirow[t]{2}{*}{$>0.05$} \\
\hline No (10) & 299.80 & 15.999 & & \\
\hline \multicolumn{5}{|c|}{ Whether suffering from back pain } \\
\hline Yes (85) & 291.95 & 27.444 & \multirow{2}{*}{$\begin{array}{l}\mathrm{t}=.271 \\
\text { d.f. }=108\end{array}$} & \multirow{2}{*}{$>0.05$} \\
\hline No (25) & 290.24 & 29.091 & & \\
\hline \multicolumn{5}{|c|}{ Whether suffering from rheumatic fever } \\
\hline Yes (30) & 287.23 & 28.119 & \multirow{2}{*}{$\begin{array}{l}\mathrm{t}=-1.004 \\
\text { d.f. }=108\end{array}$} & \multirow{2}{*}{$>.05$} \\
\hline No (80) & 293.19 & 27.543 & & \\
\hline \multicolumn{5}{|c|}{ Whether suffering from tremor in hands } \\
\hline Yes $(05)$ & 271.00 & 15.215 & \multirow{2}{*}{$\begin{array}{l}\mathrm{t}=-1.714 \\
\text { d.f. }=108\end{array}$} & \multirow{2}{*}{$>0.05$} \\
\hline No (105) & 292.54 & 27.821 & & \\
\hline \multicolumn{5}{|c|}{ Whether feeling lean and thin } \\
\hline Yes (89) & 292.40 & 27.401 & \multirow{2}{*}{$\begin{array}{l}\mathrm{t}=.654 \\
\text { d.f. }=108\end{array}$} & \multirow{2}{*}{$>.05$} \\
\hline No (21) & 288.00 & 29.353 & & \\
\hline \multicolumn{5}{|c|}{ Whether suffering from senseless or severe pain in any extremities } \\
\hline Yes (29) & 293.41 & 30.221 & \multirow{2}{*}{$\begin{array}{l}\mathrm{t}=.418 \\
\text { d.f. }=108\end{array}$} & \multirow{2}{*}{$>.05$} \\
\hline No (81) & 290.90 & 26.909 & & \\
\hline
\end{tabular}

Table IV: Distribution of respondents by presence of facing small accidents and quality of work life 


\begin{tabular}{|l|r|r|l|l|}
\hline \multirow{2}{*}{$\begin{array}{c}\text { Whether facing small } \\
\text { accidents }\end{array}$} & \multicolumn{2}{|c|}{ Quality of work life } & \multirow{2}{*}{ Significance } & \multirow{2}{*}{$\mathrm{p}$ - value } \\
\cline { 2 - 3 } & Mean & SD & & \\
\hline Yes (88) & 290.53 & 27.708 & $\mathrm{t}=-.778$ & $>0.05$ \\
\hline No (22) & 295.68 & 27.926 & d.f. $=108$ & \\
\hline
\end{tabular}

Table V: Distribution of respondents by sleep related problems and quality of work life

\begin{tabular}{|c|c|c|c|c|}
\hline \multirow[t]{2}{*}{ Whether lazy or sleepy } & \multicolumn{2}{|c|}{ Quality of work life } & \multirow[t]{2}{*}{ Significance } & \multirow[t]{2}{*}{$\mathrm{p}-$ value } \\
\hline & Mean & SD & & \\
\hline Yes (35) & 285.71 & 29.657 & \multirow{2}{*}{$\begin{array}{l}\mathrm{t}=-1.522 \\
\text { d.f. }=108\end{array}$} & \multirow[t]{2}{*}{$>0.05$} \\
\hline No (75) & 294.29 & 26.502 & & \\
\hline \multicolumn{5}{|c|}{ Whether feeling sleepy immediately after work } \\
\hline Yes (03) & 298.00 & 14.731 & \multirow{2}{*}{$\begin{array}{l}\mathrm{t}=.406 \\
\text { d.f. }=108\end{array}$} & \multirow{2}{*}{$>0.05$} \\
\hline No (107) & 291.38 & 27.995 & & \\
\hline \multicolumn{5}{|c|}{ Whether suffering from tiredness after awaking } \\
\hline Yes (35) & 276.77 & 25.974 & \multirow{2}{*}{$\begin{array}{l}\mathrm{t}=-4.093 \\
\text { d.f. }=108\end{array}$} & \multirow{2}{*}{$<.001$} \\
\hline No $(75)$ & 298.47 & 25.854 & & \\
\hline
\end{tabular}

Table V: Inter- correlation among the scores of Total QWL and Subject health questionnaire (total health score ) of the workers

\begin{tabular}{|c|c|c|c|c|}
\hline Scales & $\mathrm{N}$ & Mean & Std. Deviation & Total health score \\
\hline $\begin{array}{c}\text { Total score Quality of } \\
\text { Working life }\end{array}$ & 110 & 291.56 & 27.700 & $0.390(* *)$ \\
\hline Total health score & 110 & 19.8273 & 1.83673 & $-{ }^{*----}$ \\
\hline
\end{tabular}

** Correlation is significant at the 0.01 level (2-tailed). 


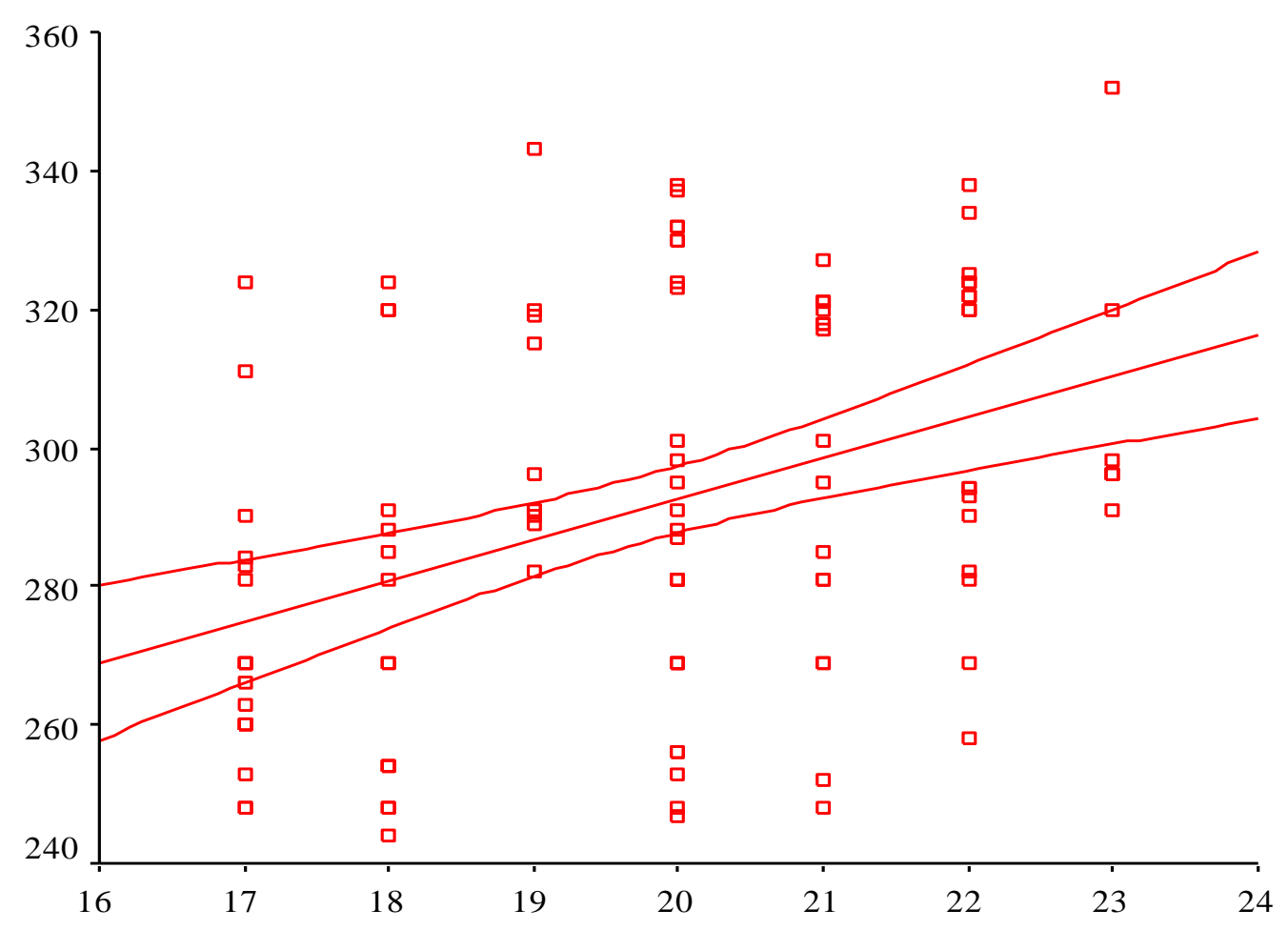

Total health score

Fig 3: Scatter diagram showing correlation between total health score and total score of quality of work life 